\title{
Impact of Arctic Wetlands on the Climate System: Model Sensitivity Simulations with the MIROC5 AGCM and a Snow-Fed Wetland Scheme
}

\author{
TOMOKO NITTA \\ Institute of Industrial Science, University of Tokyo, Tokyo, Japan \\ KEI YOSHIMURA \\ Institute of Industrial Science, and Atmosphere and Ocean Research Institute, University of Tokyo, Tokyo, Japan \\ AyAKo ABE-OUCHI \\ Atmosphere and Ocean Research Institute, University of Tokyo, Tokyo, Japan
}

(Manuscript received 3 May 2016, in final form 6 September 2017)

\begin{abstract}
Wetlands cover large areas of the middle and high latitudes and influence the surface water and energy budget, surface hydrology, and the climate system. In this study, a scheme implicitly representing a snow-fed wetland, in which snowmelt can be stored with consideration of subgrid terrain complexity, was implemented in the Minimal Advanced Treatments of Surface Interaction and Runoff (MATSIRO) land surface model. An atmospheric general circulation model (AGCM) experiment was conducted using the Model for Interdisciplinary Research on Climate, version 5 (MIROC5), with and without the wetland scheme, with the main aim of reducing the model bias of warm and dry boreal summer at mid- to high latitudes. The experiment showed not only a better surface hydrology but also a weaker land-atmosphere coupling strength and larger (smaller) latent (sensible) heat flux due to the delayed snowmelt runoff. The summer warm and dry bias was partially improved over snowy and flat areas, particularly over much of western Eurasia and North America, without an apparent deterioration of simulated surface hydrology and climate over the rest of the land in the other seasons; the mean absolute error of 2-m air temperature and precipitation over land at $45^{\circ}-90^{\circ} \mathrm{N}$ in summer decreased by $19 \%$ and $4 \%$, respectively. The next step of model development will involve implementing an explicit representation of subgrid-scale surface water and related processes.
\end{abstract}

\section{Introduction}

Land areas exhibit complex processes in the cryosphere, hydrosphere, and the land surface itself, which all interact with the climate system through complex interactions and feedbacks (Seneviratne et al. 2010). Understanding the land-atmosphere coupling strength, the degree to which anomalies in the land surface can affect atmospheric processes, is important because this coupling modulates the climate system and, hence, is a key element of climate models (Koster et al. 2006, 2010; Seneviratne et al. 2013; van den Hurk et al. 2016).

One of the issues inherent in climate modeling is model bias. The warm bias in the surface air temperature over land during the boreal summer is well known from many

Corresponding author: Tomoko Nitta, t-nitta@iis.u-tokyo.ac.jp climate modeling experiments (Christensen and Boberg 2012; Mueller and Seneviratne 2014; Cheruy et al. 2014). Mueller and Seneviratne (2014) examined land climate and evapotranspiration biases in the Coupled Model Intercomparison Project phase 5 (CMIP5; Taylor et al. 2012) experiments and found that evapotranspiration was underestimated and surface air temperature was overestimated in most regions during the boreal summer. In addition, they showed that precipitation at middle and high latitudes was underestimated in western Eurasia and northeastern North America and overestimated in eastern Eurasia and Alaska. Cheruy et al. (2014) examined this CMIP5 summer warm bias and found that it is especially strong in regions where the coupling between soil moisture and the atmosphere is also strong.

To improve climate model simulation over land areas, understanding the land-atmosphere coupling 
strength is necessary. An accurate representation of land processes may improve evapotranspiration estimates and, hence, the climate in land areas (e.g., temperature and precipitation).

Land surface modeling is a typical way to investigate land-atmosphere coupling. However, insufficient detail in land surface models causes uncertainties and bias in the simulation of surface processes, which may impact the understanding of land-atmosphere coupling and may lead to bias in climate models.

These uncertainties include deficiencies in the parameterization of soil hydrology (Campoy et al. 2013) and lack of irrigation that can cause bias in soil moisture or discrepancies in surface albedo that cause a net radiation bias. Cheruy et al. (2014) also mentioned the summer soil moisture deficit, which may originate from a winter precipitation deficit, as a source of dispersion for Northern Hemisphere summer temperatures in CMIP5 experiments.

In this study, we focused on surface hydrology after snowmelt and examined the effects of snow-fed wetlands that constitute storage on surface hydrology and climate. Wetlands, aside from lakes and reservoirs, cover more than $5 \%$ of the land area globally, and their distribution peaks at high northern latitudes, despite a large uncertainty (Lehner and Döll 2004). The role of wetlands is important in surface hydrology, the climate system, and the global carbon cycle. In terms of surface hydrology, lakes and wetlands store surface water, modulate runoff and river discharge, and influence evaporation (Bowling and Lettenmaier 2010). Wetlands affect the speed of horizontal water transfer at the subgrid scale, which is often poorly represented in land surface and climate models, despite affecting summer soil moisture and surface wetness at high latitudes.

Through the surface energy budget, changes in evaporation (latent heat flux) due to changes in surface wetness may affect surface energy fluxes, particularly sensible heat flux. Wetlands may also affect the climate over land through land-atmosphere coupling that may be changed due to the change of variability of surface wetness. The magnitude of land-atmosphere coupling strength is still in discussion; it tends to be weak in reality but strong in models (Ferguson et al. 2012).

Additionally, the slow decomposition rate of organic matter in wetlands leads to an increase in the soil carbon pool; as such, lakes and wetlands at high latitudes are important sources of methane emissions (Melton et al. 2013; Kirschke et al. 2013; Wik et al. 2016). Therefore, sufficient representation of lakes and wetlands in Earth system models that simulate the interaction of Earth's biogeochemical cycles with the climate system is crucial.
There are several different wetland schemes used in land surface models and large-scale hydrological models. The TOPMODEL (Beven and Kirkby 1979) approach has been used widely to estimate the dynamic wetland fraction. For example, Kleinen et al. (2012) developed a wetland module based on TOPMODEL to assess peat accumulation and its influence on the global carbon cycle. Bowling and Lettenmaier (2010) developed a lakes and wetlands scheme, incorporated it into the Variable Infiltration Capacity (VIC) hydrological model (Liang et al. 1994), and showed improved streamflow simulation from Arctic catchments. Stacke and Hagemann (2012) developed a global dynamic wetland extent scheme and evaluated it globally. Balsamo et al. (2012) investigated the impact of lakes in numerical weather prediction using the Freshwater Lake model (FLake) model. Krinner (2003) showed the effects of surface water in lakes and wetlands at high latitudes on simulated surface air temperature, cloud cover, geopotential height, and precipitation using an atmospheric general circulation model (AGCM).

The aim of our study was similar to that of Krinner (2003): implementing a wetlands scheme into the Minimal Advanced Treatments of Surface Interaction and Runoff (MATSIRO; Takata et al. 2003; Nitta et al. 2014) land surface model and examining the impact of Arctic wetlands on surface hydrology and climate. Model sensitivity analysis was conducted using the AGCM of the Model for Interdisciplinary Research on Climate, version 5 (MIROC5; Watanabe et al. 2010). Multiple recent reference datasets were used to evaluate the results; additionally, we evaluated river discharge and landatmosphere coupling strength. Whether the abovementioned climate model bias in the current generation of climate model would be reduced by the representation of snow-fed wetlands in the model was also examined.

This study addressed the following questions:

1) How does the aforementioned effect of Arctic wetlands improve the simulation of surface hydrology in an atmospheric-land coupled model?

2) How does it affect land-atmosphere coupling?

3) How does it decrease the bias in boreal summer surface air temperature and precipitation in the AGCM?

Section 2 describes the methodology, including the MIROC5 climate model and its respective land surface model, the wetland scheme, experimental design, validation data, and analysis methods. In sections $3 a-c$, we compare simulated soil moisture, evapotranspiration, and river discharge with corresponding reference datasets. The effect of wetlands on the land climate bias is 
examined in section $3 \mathrm{~d}$ using a dataset from the Climate Research Unit (CRU; Harris et al. 2014). In sections $4 \mathrm{a}-\mathrm{c}$, we discuss the surface energy budget, the landatmosphere coupling strength during the convective season, and latitudinal dependence of model sensitivity based on two simulations. We discuss future work in section 4d. Finally, summary and conclusions are given in section 5 .

\section{Methods}

\section{a. MIROC5 and MATSIRO}

MIROC5 is a global climate model developed jointly by the Atmosphere Ocean Research Institute at the University of Tokyo, the National Institute for Environmental Studies, and the Japan Agency for Marine-Earth Science and Technology. It participated in CMIP5, and its simulation results were used in various studies cited by the Intergovernmental Panel on Climate Change (IPCC) Fifth Assessment Report (IPCC 2013). Watanabe et al. (2010) provides further details about MIROC5.

MATSIRO is the land model for MIROC5. It has been used for climate studies at the global and regional scales (Takata et al. 2009; Yamada et al. 2013), as well as studies concerning water resources, flood risk, and sea level change (Hirabayashi et al. 2008; Yoshimura et al. 2008; Pokhrel et al. 2012). In the latest version of MATSIRO, land use is defined using three tiles: potential vegetation, cropland, and lakes (Watanabe et al. 2010). Potential vegetation is defined according to the vegetation types of the Simple Biosphere Model 2 (SiB2; Sellers et al. 1996) scheme and has 10 categories including land ice, as shown in Fig. 1. There is no wetland category for land cover in the original SiB2 vegetation types or soil types. Monthly climatology of leaf area index (LAI) for potential vegetation and cropland areas is used to account for seasonal variation via the Moderate Resolution Imaging Spectroradiometer (MODIS) LAI product (Shabanov et al. 2005). Both potential vegetation and cropland tiles consist of six soil layers, up to three snow layers, and a single canopy layer, driving predictions of the temperature and amount of water in the canopy, soil, and snow. The freezing and melting of soil water are also considered. As shown in the gray box in the upper-left part of Fig. 2, water inflow to the soil surface goes to infiltration or to surface runoff directly to rivers. The kinematic wave equation is used for river routing (Ngo-Duc et al. 2007).

\section{b. Wetland scheme}

A flowchart of our wetland scheme is shown in Fig. 2. To examine the effects of wetlands on surface hydrology

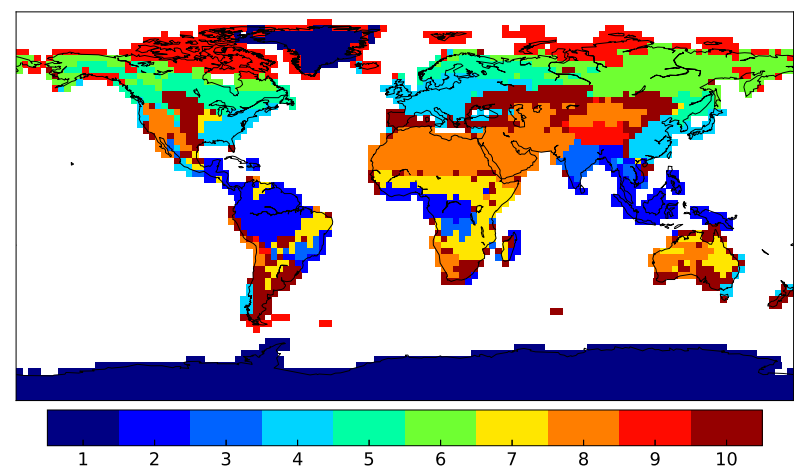

FIG. 1. Land cover of the potential vegetation tiles used in this study: 1) continental ice, 2) broadleaf evergreen forest, 3) broadleaf deciduous forest and woodland, 4) mixed coniferous and broadleaf deciduous forest and woodland, 5) coniferous forest and woodland, 6) high-latitude deciduous forest and woodland, 7) wooded C4 grassland, 8) shrubs and bare ground, 9) tundra, and 10) $\mathrm{C} 3$ grassland.

and the climate on land, we developed a wetlands scheme that represented two major effects: 1) the storage of part of the surface water and delay of runoff to rivers and 2) an increase in land surface wetness and hence evaporation in water-limited regimes. For the first effect, a tank is introduced that temporarily stores part of the surface runoff. For the second effect, the runoff from the tank is calculated [see Eq. (1)] and added to water inflow to the soil surface (i.e., precipitation that passes through canopy gaps, water drops from the canopy, and snowmelt water), so that the land surface tends to get wetter. It should be noted that only snow-fed wetlands are considered in this study because our research target is high latitudes, and the hydrographs at high latitudes are characterized by a large peak during snowmelt season (also described in section 3c).

When snowmelt occurs, a part of the surface runoff goes directly to rivers and the remaining surface runoff is stored by the added tank (i.e., snow-fed wetlands). The ratio of surface runoff that goes directly to rivers is represented by $\alpha$. The outflow from the tank is calculated using a time constant and is then added to the water flowing into the soil surface. The storage of the tank is represented as

$$
\frac{d S}{d t}=-\frac{S}{\tau}+(1-\alpha) R_{s},
$$

where $R_{s}$ is surface runoff calculated by MATSIRO; $t$ is the time; and $\alpha$ and $\tau$ are parameters related to the inflow and outflow of the surface tank, respectively. To represent snow-fed wetlands, which tend to be formed on flat areas, a spatially dependent time constant $\tau$ is introduced. Parameter $\tau$ determines the outflow from 


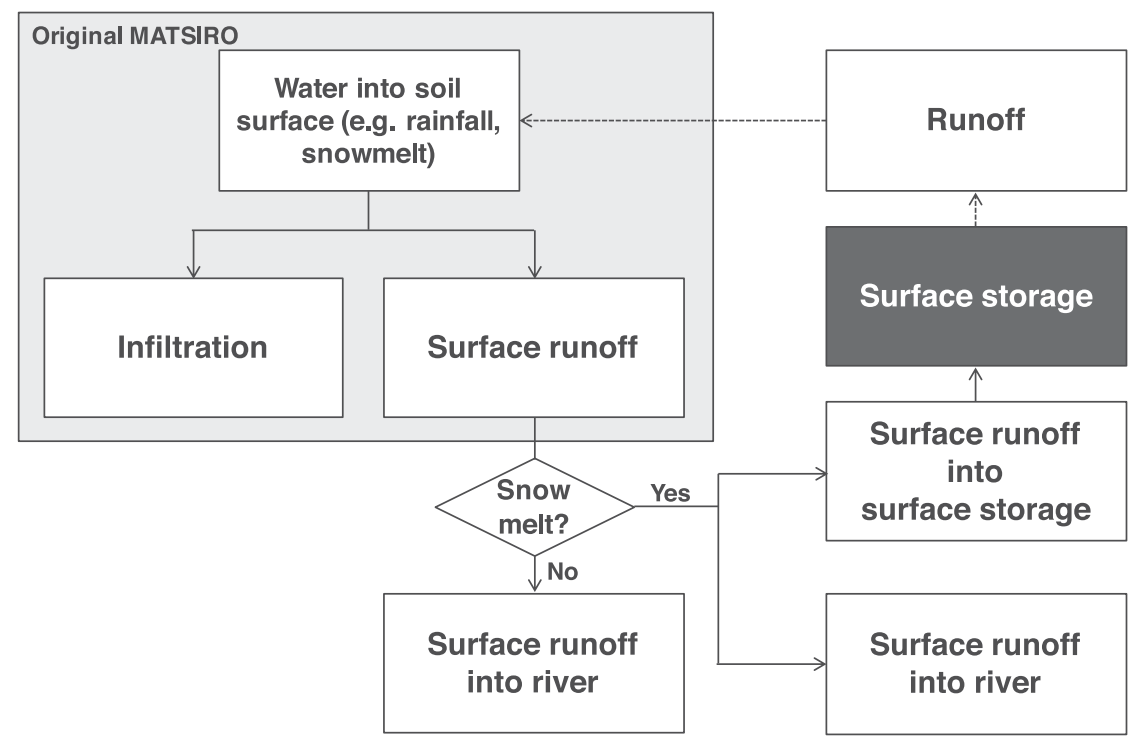

FIG. 2. Flowchart of the original MATSIRO model (in the upper-left corner) and the new scheme that includes the wetland scheme (which is covered by the whole diagram).

the surface tank and a function of the standard deviation of elevation above sea level is applied:

$\tau=\max \left(\tau_{0}\left\{1-\min \left[\operatorname{zsd}(x), \operatorname{zsd}_{\text {max }}\right] / \operatorname{zsd}_{\text {max }}\right\}, \Delta t\right)$,

where $\tau_{0}$ is the maximum of the time constant, zsd is the standard deviation of elevation above sea level within each grid at point $x$, and $\Delta t$ is the time step of the model.

Parameter zsd is a physical parameter calculated by a topography dataset, with a higher spatial resolution than the simulation, and $\tau_{0}, \mathrm{zsd}_{\max }$, and $\alpha$ are tunable parameters. The function and parameter values were determined based on sensitivity simulations using an offline land model with perturbed parameters; 1 month, $200 \mathrm{~m}$, and 0.1 were chosen as the most appropriate values for $\tau_{0}, \mathrm{zsd}_{\max }$, and $\alpha$, respectively (Nitta et al. 2015).

It should be noted that this wetland scheme is simpler than the schemes used in previous studies, because our focus was on examining the effects of wetlands in current generation climate models. We believe our scheme is sufficient for this purpose, with the development of more sophisticated models being beyond the scope of this work (see section $4 \mathrm{~d}$ ).

\section{c. Experimental design}

\section{1) EXPERIMENTAL SETTINGS}

Two AGCM experiments were conducted using MIROC5, one with and the other without the wetlands scheme [hereafter referred to as the simplified wetlands
(SW) experiment and control (CTL) experiment, respectively]. We always applied the wetland scheme everywhere except in land ice grids. The spatial resolution is T42, which corresponds to a gridcell size of about $310 \mathrm{~km}$ at the equator, and the model has 40 levels in the vertical. We used climatological monthly sea surface temperature (SST) and sea ice distributions from 1979 to 1996 as boundary conditions. We conducted a 30 -yr simulation with zero surface storage as an initial condition and excluded the first 10 years from the analysis as a spinup.

\section{2) VALIDATION}

Both CTL and SW were validated against multiple datasets. An analysis mask was created to exclude land ice grids because we did not apply the wetland scheme to these grids. First, the impacts of wetlands on simulated warm season soil moisture, evapotranspiration, and river discharge were validated using the reference datasets described below. We present global maps of reference datasets, results of the CTL and SW simulations, biases of the two simulations, and the difference between the simulations. To analyze the difference between models, grids that differ at the $5 \%$ significance level are indicated. In this study, bias is defined as the difference between reference data and simulation results.

Simulated soil moisture in the first layer was compared to the Essential Climate Variable (ECV) surface soil moisture dataset; this product combines several satellite-based soil moisture datasets (Liu et al. 2012; Wagner et al. 2012). We used the 
evapotranspiration dataset from the LandFlux-EVAL project (Mueller et al. 2013) as a reference to validate evapotranspiration. This dataset is a synthesis of diagnostic datasets, land surface models, and reanalyses. The products only from the diagnostic datasets were used for comparison.

We used river discharge data from the Global Runoff Data Centre (GRDC). Because our focus was on high latitudes and the horizontal resolution was low (T42), we used river discharge data from downstream observation stations with relatively large catchment areas for eight major rivers: the Yukon, Mackenzie, Volga, Ob, Yenisey, Lena, Amur, and Kolyma. All of these rivers are situated at the high latitudes of the Northern Hemisphere. It may be worthwhile to explain the topographical and climatological characteristics of these river basins. The lowest relief is found in Volga followed by $\mathrm{Ob}$, and the highest relief is found in Yukon. The annual snowfall in the CTL experiment is the highest in Yukon and the lowest in Lena, followed by Amur and Yenisey. The climatological monthly river discharge was calculated from 1979 to 1996, with missing data excluded, and compared for the two simulations. Rootmean-square difference (RMSD) and correlation coefficients were used to evaluate the seasonality of river discharge.

We used the CRU 2-m air temperature and precipitation dataset (Harris et al. 2014) to evaluate land climate bias, for which mean absolute error (MAE) was used as a metric. The CRU data are interpolated into the T42 grid by bilinear interpolation to match the simulation.

\section{3) THE LAND-ATMOSPHERE COUPLING} STRENGTH AND ATMOSPHERIC WATER BUDGET

The land-atmosphere coupling strength has been evaluated using ensemble AGCM experiments, offline land experiments, reanalyses, and observations with various indices (Koster et al. 2004; Dirmeyer 2011; Ferguson et al. 2012). In our study, we evaluated the land-atmosphere coupling strength using the index " $\tau_{\text {SM-LCL }}, \tau_{\text {SM-EF }}, \tau_{\text {EF-LCL }}$ " proposed by Ferguson et al. (2012), which is based on the rank correlation coefficient of soil moisture (SM), evaporative fraction (EF), and the lifting condensation level (LCL) during the convective season. We chose this method because it has previously been applied to satellite observations, allowing us to compare simulated land-atmosphere coupling with these estimates.

Following the protocol of Ferguson et al. (2012), we first defined the convective season in each grid as the calendar months by which a cumulative $80 \%$ of annual convective events have occurred and which independently accounted for more than $10 \%$ of convective events. Convective events were characterized as rain events with a $45 \%$ or greater convective rainfall fraction. The simulated convective season map was similar to one based on observations (Ferguson et al. 2012, their Fig. 1d). The first layer soil moisture at 0130 local time and EF and LCL at 1330 local time during the convective season were then calculated. EF was calculated using

$$
\mathrm{EF}=\frac{\mathrm{LE}}{\mathrm{LE}+H},
$$

where LE is the latent heat flux and $H$ the is sensible heat flux. The lifting condensation level, the mean height of the cloud base for air parcels lifted from the surface (Betts 2004), was calculated from the surface air temperature, specific humidity, and surface pressure, following Eqs. (6)-(9) in Ferguson et al. (2012).

In addition, we used the atmospheric water budget (Oki et al. 1995) to determine the contribution of local evapotranspiration and moisture convergence to changes in precipitation:

$$
\begin{aligned}
& C_{\text {conv }}=\frac{\Delta(-\nabla \mathbf{Q})}{\Delta P} \times 100, \\
& C_{\text {evap }}=\frac{\Delta E}{\Delta P} \times 100,
\end{aligned}
$$

where $C_{\text {conv }}$ and $C_{\text {evap }}(\%)$ are the contribution of moisture convergence and local evapotranspiration, respectively; $\Delta P$ is the change in precipitation; and $\Delta E$ is the change in evapotranspiration. The vertically integrated moisture flux $\mathbf{Q}$ is derived by integrating the product of specific humidity and wind velocity with respect to pressure. The change in convergence is $\Delta(-\nabla \mathbf{Q})$.

\section{4) SENSITIVITY ANALYSIS}

Last, we conducted an analysis of soil moisture, evapotranspiration, 2-m air temperature, and precipitation in June-August (JJA) to examine the factors that affect model performance or sensitivity in regions with snow. In this analysis, we focused on the grids at high latitudes $\left(48^{\circ}-72^{\circ}\right)$, where the differences in all three variables of JJA climatology between the CTL and SW simulations are significant at the $5 \%$ level. As a result, we selected 183 grids, mainly in western Eurasia (Fig. 11d below). Then, we plotted the difference in soil moisture $\Delta W$ against the difference in evapotranspiration $\Delta E, 2-\mathrm{m}$ air temperature $\Delta \mathrm{T} 2$, and precipitation $\Delta P$ between the CTL and SW simulations for each grid. We categorized these plots by elevation, standard deviation of elevation, snow water equivalent, and latitude. Linear regression 


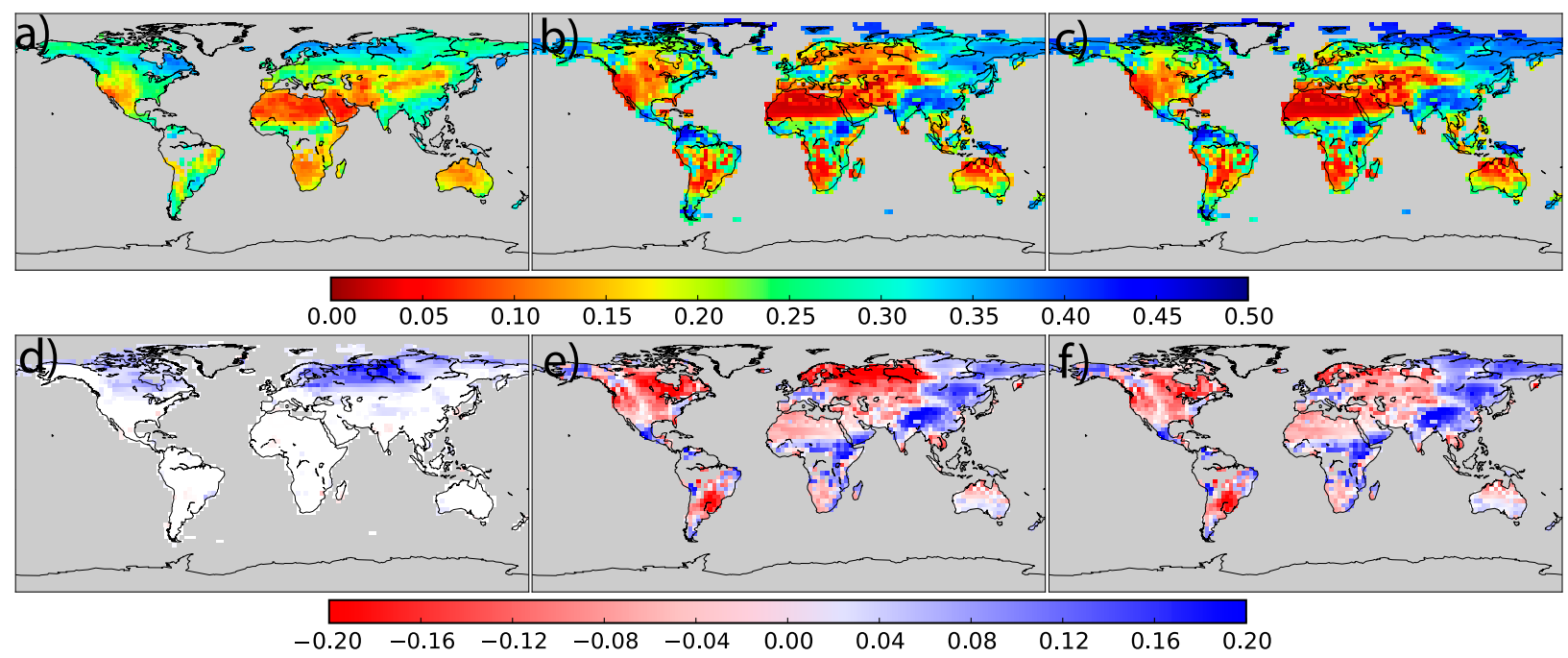

FIG. 3. Climatological soil moisture $\left(\mathrm{m} \mathrm{m}^{-1}\right)$ in JJA: (a) ECV-SM satellite surface soil moisture observation for 1981-2000, (b) firstlayer soil moisture from the CTL simulation, (c) first-layer soil moisture from the SW simulation, (d) significant differences between the two simulations (SW minus CTL) at the 5\% level, (e) differences between ECV-SM and the CTL simulation (CTL minus ECV-SM), and (f) differences between ECV-SM and the SW simulation (SW minus ECV-SM). A gray mask is applied to regions where ECV-SM data are missing in (a), where there are sea and ice grids in (b)-(d), or for both in (e) and (f).

lines were shown only when the correlation coefficient for that category is larger than 0.3 .

\section{Results}

\section{a. Soil moisture}

The climatological soil moisture in JJA from ECV SM, results of the CTL and SW simulations, the difference between the two simulations, and the difference between each simulation and ECV SM are presented in Fig. 3. The ECV SM during JJA exhibits its wettest values in western Eurasia and eastern North America at high latitudes (approximately 0.35-0.4). The CTL simulation shows a different spatial distribution from the ECV SM. A wet bias was found in eastern Eurasia and over Alaska. A dry bias was found in western Eurasia and North America, particularly at high latitudes (the underestimation of JJA soil moisture was greater than 0.2 in these regions). These wet and dry biases might be caused by overestimated and underestimated precipitation, respectively, as we discuss in section 3c.

By including the effects of wetlands, soil moisture increased at high latitudes, particularly in western Eurasia due to the flat topography and high maximum snow depth. The severe dry bias in western Eurasia was improved, but the wet bias in eastern Eurasia was slightly more pronounced. In our simulation, "soil moisture" included soil moisture itself and surface water because the surface water tanks influence the soil moisture. Lakes were counted as independent water bodies. It is difficult to quantitatively separate the increase in soil moisture into the effects of the surface water tank (i.e., wetlands) and the increase in soil moisture caused by the increase in precipitation. However, western Eurasia, where the soil moisture increase was the highest, corresponds to the region of dry bias in the CTL simulation, which might positively impact evapotranspiration and land climate biases.

\section{b. Evapotranspiration}

Figure 4 shows the climatological JJA mean evapotranspiration from the LandFlux-EVAL diagnostic data, CTL simulation, SW simulation, the difference between the two simulations, and the difference in each simulation and the reference data. At high latitudes, there was latitudinal variation in the reference data from $<1$ to about $2.5 \mathrm{~mm} \mathrm{day}^{-1}$ in Eurasia. The simulated evapotranspiration in the CTL experiment captured the latitudinal gradient. However, the longitudinal variation differed from the reference data. The evapotranspiration bias (Fig. 4e) had a distinct spatial distribution that was similar to the soil moisture bias, with an underestimation in western Eurasia and an overestimation in eastern Eurasia. By incorporating the effects of wetlands, evapotranspiration in western Eurasia increased by about $1 \mathrm{~mm}$ and the dry bias in western Eurasia was reduced.

\section{c. River discharge}

Figure 5 compares the 20-yr monthly mean of river discharge outputs against GRDC observations in the downstream region of eight major rivers at northern high latitudes: the Yukon, Mackenzie, Volga, Ob, Yenisey, 

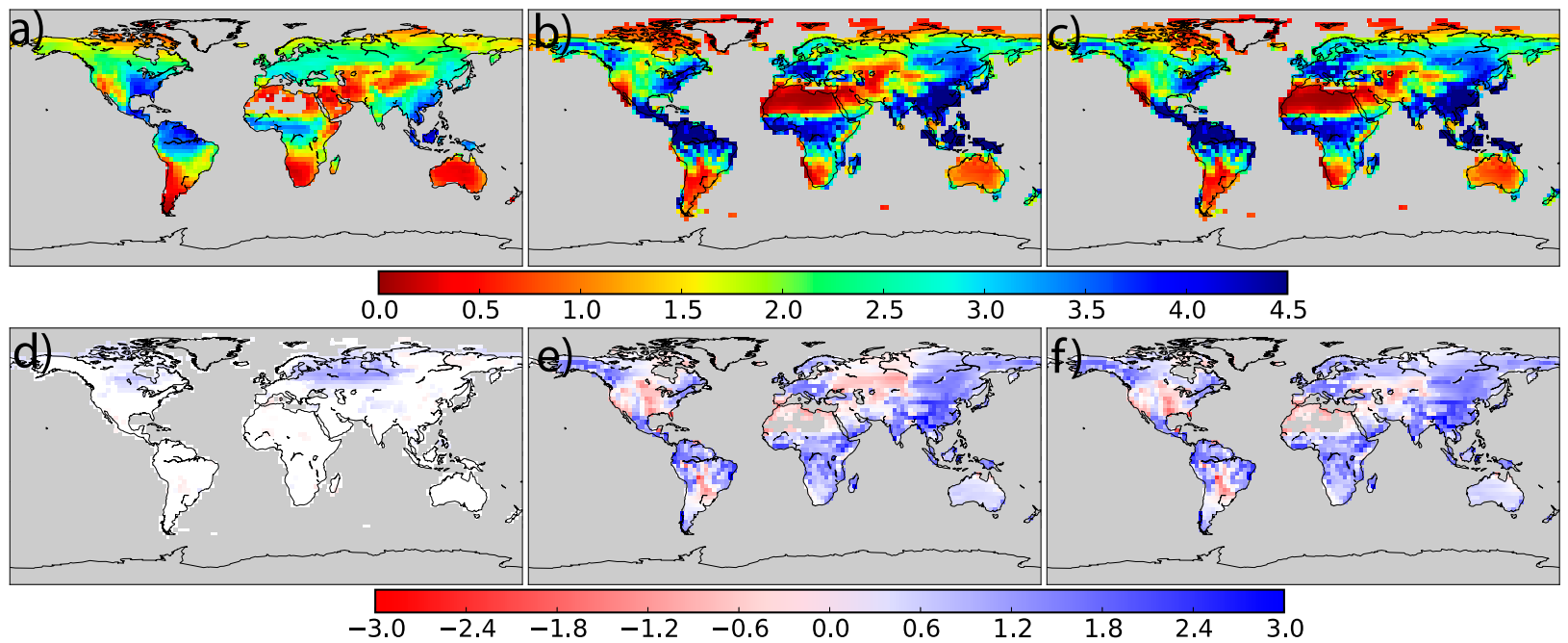

FIG. 4. Climatological evapotranspiration $\left(\mathrm{mm} \mathrm{day}^{-1}\right.$ ) in JJA: (a) LandFlux-EVAL diagnostic dataset for 1989-2005, (b) CTL simulation, (c) SW simulation, (d) differences between the two simulations (SW minus CTL) at the 5\% significance level, (e) differences between LandFlux-EVAL and the CTL simulation (CTL minus LandFlux-EVAL), and (f) differences between LandFlux-EVAL and the SW simulation (SW minus LandFlux-EVAL).A gray mask is applied to regions where LandFlux-EVAL data are missing in (a), where there are sea and ice grids in (b)-(d), or for both in (e) and (f).

Lena, Amur, and Kolyma. GRDC observed river discharge data had a clear peak in summer, which is due primarily to snowmelt runoff. The peak of river discharge in the CTL simulation was 1 month earlier than the observations for all rivers except the Amur (Table 1) and was larger than the observations in most rivers. In a previous study using an offline land simulation without wetlands included, MATSIRO simulated snow melting more slowly than observations (Nitta et al. 2014). Therefore, an early peak bias in river discharge implies that the runoff process of snowmelt water is not well represented in the model.

By incorporating the wetland scheme, the timing of peak discharge became 1 month slower and was in accordance with the observations in three of the eight rivers. The timing of peak discharge did not change for other rivers. The peak discharge was lower in the SW simulation than CTL for all of the catchments. It was lower than the observations in the Yenisey and Lena and higher than the observations in the Yukon, Mackenzie, Amur, and Kolyma. Simulated river discharge was much closer to the SW simulation than the CTL simulation in the $\mathrm{Ob}$ and Volga rivers because timing of peak discharge is earlier than observations for all rivers in CTL, and the flat terrain and relatively high snowfall in these river basins have the largest delay impact on runoff. This was confirmed by the RMSD between the observation and each simulation; the RMSD was reduced (maximum reduction was $-14400 \mathrm{~m}^{3} \mathrm{~s}^{-1}$ in the $\mathrm{Ob}$ River, and the minimum reduction was $-535 \mathrm{~m}^{3} \mathrm{~s}^{-1}$ in the Kolyma River). In addition, the correlation coefficient had increased for all rivers; the number of rivers with significant correlation coefficients at the $1 \%(0.708, n=12)$ and $5 \%(0.576, n=12)$ levels rose from one to four and from four to five, respectively.

\section{d. Land climate biases}

In this subsection, we examine the surface air temperature and precipitation bias simulated by the MIROC5 AGCM, with and without the wetland scheme. Because of computational limitations, we used an AGCM simulation rather than atmosphere-ocean coupled GCM simulation. The climatology of the 2-m air temperature in JJA from the CRU, the CTL simulation, the SW simulation, the difference between the two simulations, the difference in the CTL simulation and CRU, and the difference in the SW simulation and CRU are shown in Fig. 6. The CTL temperature reproduced the spatial variation shown in CRU data but had a warm bias over land, particularly in western Eurasia and eastern North America. It was over $10 \mathrm{~K}$ in the most severe regions.

The inclusion of the wetland scheme reduces the warm bias. The reduction of the 2-m air temperature corresponded to the difference in evapotranspiration in Fig. 4d, but also extended to eastern Eurasia. The increased evapotranspiration led to a decrease in the sensible heat flux and hence the 2-m air temperature. In addition, cloud cover was increased in the SW simulation, and it reduced the incoming shortwave radiation significantly in western Eurasia (not shown). Table 2 shows the MAE of the 2-m air temperature between CRU and the simulations from the CTL and SW experiments over land at $45^{\circ}-90^{\circ} \mathrm{N}$ for each season. The difference in the MAE was smaller in the other seasons 


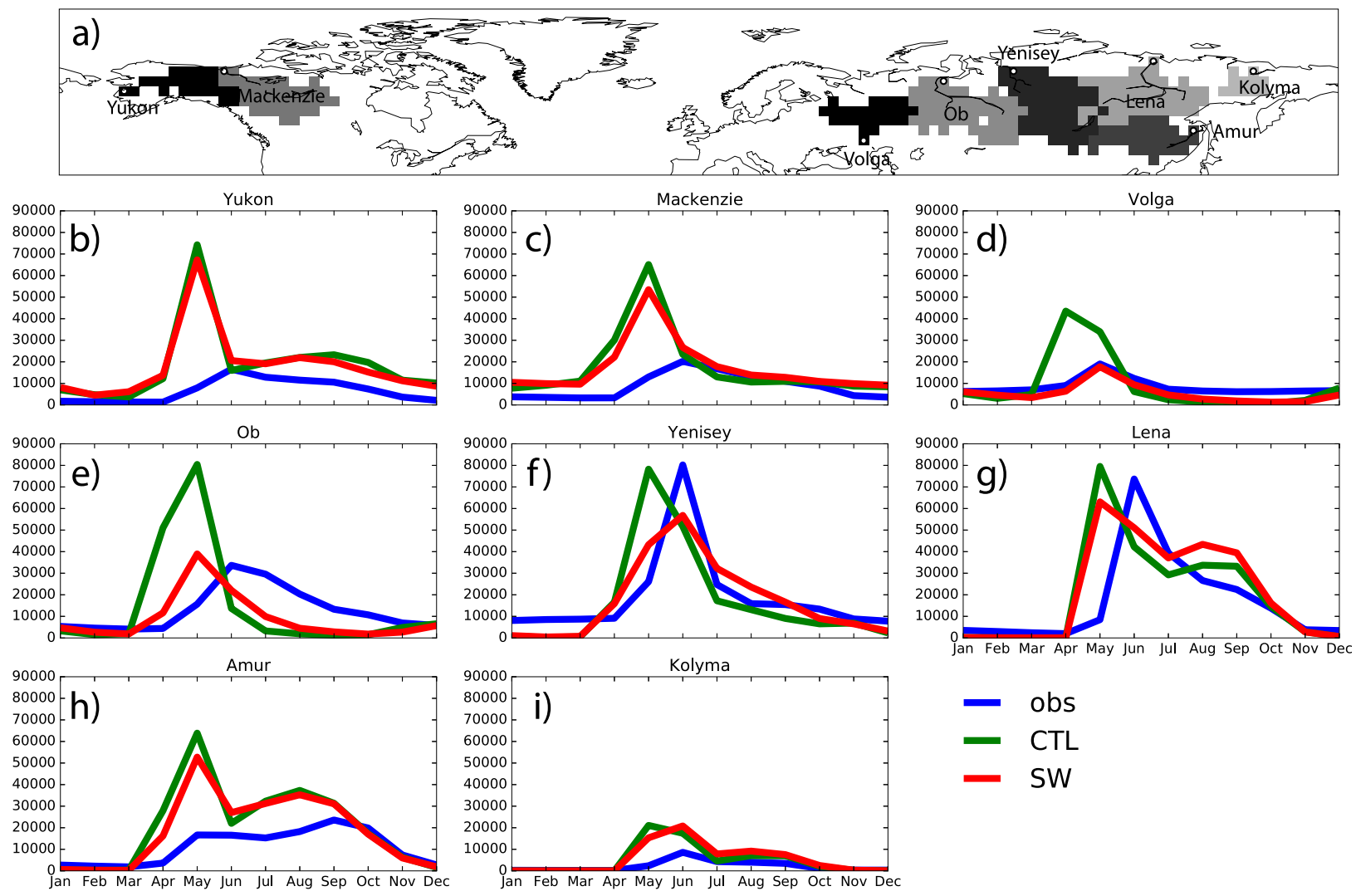

FIG. 5. Monthly climatological data of river discharge $\left(\mathrm{m}^{3} \mathrm{~s}^{-1}\right)$ in eight major river basins at high latitudes: (a) GRDC observation sites (dots) and upstream river basins (shading) fitted to a T42 resolution river map. River basins: (b) Yukon, (c) Mackenzie, (d) Volga, (e) Ob, (f) Yenisey, (g) Lena, (h) Amur, and (i) Kolyma; on the map, the river basins are shown from west to east.

than in JJA, with a slight increase (0.03K) in March-May (MAM) and a slight decrease in September-November (SON) and December-February (DJF).

The climatology of precipitation in JJA from CRU, the CTL simulation, the SW simulation, the difference between the two simulations, the difference between the CTL simulation and CRU, and the difference between the SW simulation and CRU is shown in Fig. 7. Again, the difference in the CTL simulation and CRU showed a similar wet and dry bias in Eurasia and North America.

The difference between the CTL and SW simulation showed an overall noisier spatial distribution than other variables: both an increase and decrease over land and ocean. However, an increase in precipitation was found over western Eurasia. The difference in the MAE of precipitation for each season was largest in JJA and displayed a similar tendency to the 2-m air temperature (Table 2).

\section{Discussion}

\section{a. Surface energy budget}

We evaluated surface energy fluxes to determine the reasons for the decrease in the 2-m air temperature.
Figure 8 shows the difference in each component of the surface energy budget averaged over the eight major river basins at high latitudes. The maximum difference was found over the Volga and Ob River basins. Downward shortwave radiation and upward longwave radiation decreased. Net radiation increased because the decrease in upward longwave radiation was larger than the decrease in incoming shortwave radiation. The

TABLE 1. Metrics of river discharge: RMSD $\left(\mathrm{m}^{3} \mathrm{~s}^{-1}\right)$, correlation coefficient (CC), and error in timing of peak discharge (ETPD; month).

\begin{tabular}{lrrcccr}
\hline \hline \multicolumn{1}{c}{ River } & $\begin{array}{r}\text { RMSD } \\
(\mathrm{CTL})\end{array}$ & $\begin{array}{c}\text { RMSD } \\
(\mathrm{SW})\end{array}$ & $\begin{array}{c}\text { CC } \\
(\mathrm{CTL})\end{array}$ & $\begin{array}{c}\text { CC } \\
(\mathrm{SW})\end{array}$ & $\begin{array}{r}\text { ETPD } \\
(\mathrm{CTL})\end{array}$ & $\begin{array}{r}\text { ETPD } \\
(\mathrm{SW})\end{array}$ \\
\hline Yukon & 20737 & 18633 & 0.35 & 0.40 & -1 & -1 \\
Mackenzie & 17369 & 13643 & 0.31 & 0.48 & -1 & -1 \\
Volga & 11530 & 3240 & 0.64 & 0.95 & -1 & 0 \\
Ob & 25917 & 11487 & 0.00 & 0.43 & -1 & -1 \\
Yenisey & 18178 & 10111 & 0.65 & 0.86 & -1 & 0 \\
Lena & 23001 & 18521 & 0.48 & 0.66 & -1 & -1 \\
Amur & 17288 & 13527 & 0.69 & 0.80 & -4 & -4 \\
Kolyma & 6128 & 5593 & 0.72 & 0.90 & -1 & 0 \\
\hline
\end{tabular}



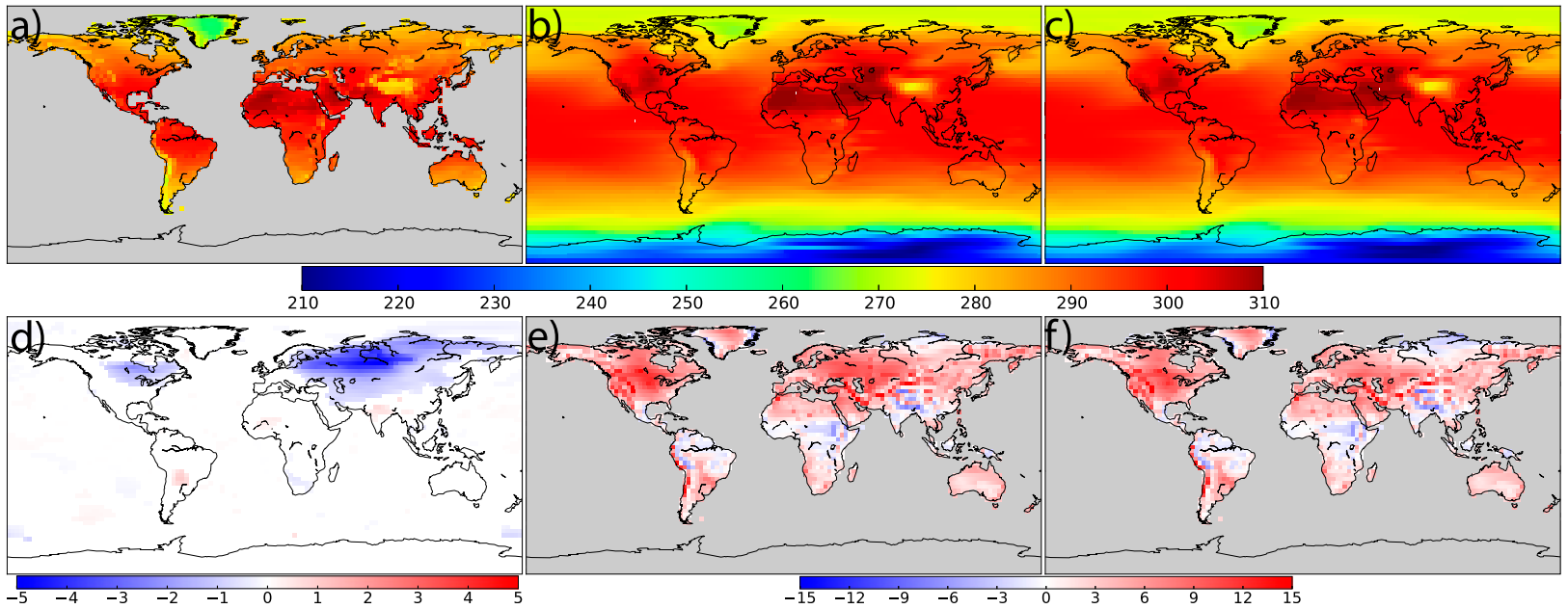

FIG. 6. Climatological surface air temperature (K) in JJA: (a) CRU observation for 1979-96, (b) CTL simulation, (c) SW simulation, (d) differences between the two simulations (SW minus CTL) with 5\% significance, (e) differences between CRU and the CTL simulation (CTL minus CRU), and (f) differences between CRU and the SW simulation (SW minus CRU).

increase in the latent heat flux led to a decrease in the sensible heat flux.

\section{$b$. The land-atmosphere coupling strength and atmospheric water budget}

Figures 9a-f show the land-atmosphere coupling strength from the CTL simulation and SW simulation, respectively. The lower panels show the difference between the two simulations. The correlation of soil moisture and the lifting condensation level $\tau_{\mathrm{SM}-\mathrm{LCL}}$ was from about -0.5 to -0.7 over much of the land area. Compared with $\tau_{\text {SM-LCL }}$ estimated from remote sensing observations by Ferguson et al. (2012), the landatmosphere coupling strength was stronger than satellite observations for SM-LCL, SM-EF, and EF-LCL.

With the inclusion of wetland effects, $\tau_{\mathrm{SM}-\mathrm{LCL}}$ became weaker by about $0.1-0.2$ in west Eurasia and was slightly closer to the observations. This is confirmed by the comparison of basin average $\tau_{\text {SM-LCL }}$ values in Table 3 . These high latitudes were an energy-limited cold region in ET estimations, where the coupling strength was generally weak. However, because of the soil moisture bias, it was too strong in the CTL simulation. In the SW simulation, on the contrary, the coupling strength became weaker and closer to the observations possibly because of the following reasons. First, the dry soil moisture bias in early spring and summer was partially resolved because of the more gradual transport of snowmelt runoff to rivers. Second, the soil moisture response to the rainfall events became less sharp because the soil was already wetter.

Figure 10 shows the contribution of the change in the vertically integrated moisture convergence and evapotranspiration to the change in precipitation. The contribution of evapotranspiration was dominant in most regions where precipitation increased.

\section{c. What determines sensitivity?}

Figures $11 \mathrm{a}-\mathrm{c}$ show the difference in soil moisture against the difference in evapotranspiration, 2-m air temperature, and precipitation. As explained in section 2, we categorized the plots by elevation, standard deviation of elevation, snow water equivalent, and latitude; the clearest relationship is with latitude, as shown in Figs. 11a-c. Grids were sorted into $4^{\circ}$ latitudinal bands. The absolute values of correlation coefficients were larger than 0.3 in all bands for the soil moisture-evapotranspiration relationship. The sensitivity ratio $\Delta W / \Delta E$, or the slope of each line, shows clear latitudinal dependence. This is because the latent heat increase depends on net radiation that changes with latitude (higher radiation is present at lower latitudes). When soil moisture increases, specific humidity at the air-land interface increases and hence evaporation increases. Because evaporation is calculated through the surface energy budget, the

TABLE 2. MAE (grid area weighted) between CRU observations and simulations from the CTL and SW experiments over land at $45^{\circ}-90^{\circ} \mathrm{N}$ for each season.

\begin{tabular}{llllll}
\hline \hline \multicolumn{1}{c}{ Variable } & Unit & MAM & JJA & SON & DJF \\
\hline 2-m air temperature (CTL) & $\mathrm{K}$ & 2.86 & 5.43 & 3.18 & 4.55 \\
2-m air temperature (SW) & $\mathrm{K}$ & 2.89 & 4.38 & 3.00 & 4.44 \\
Precipitation (CTL) & $\mathrm{mm} \mathrm{day}^{-1}$ & 0.588 & 1.006 & 0.656 & 0.481 \\
Precipitation (SW) & mm day $^{-1}$ & 0.622 & 0.962 & 0.658 & 0.459 \\
\hline
\end{tabular}



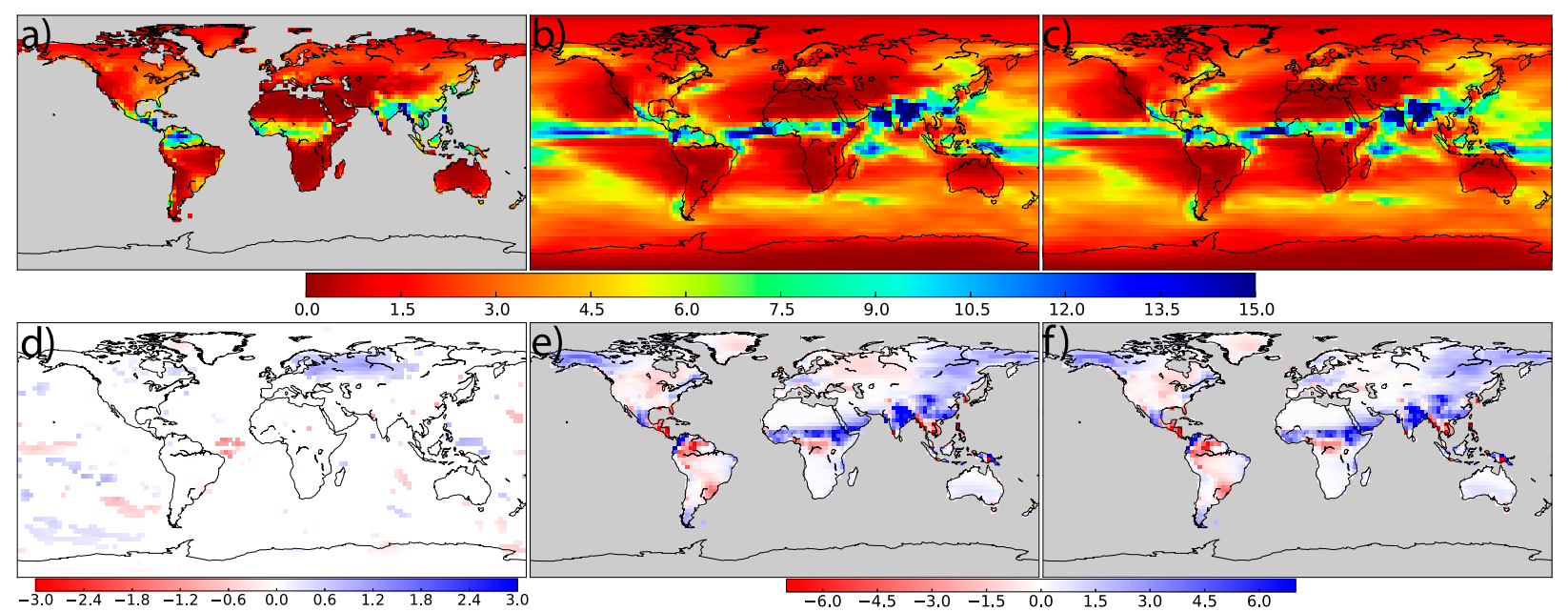

FIG. 7. As in Fig. 6, but for climatological precipitation $\left(\mathrm{mm} \mathrm{day}^{-1}\right)$.

increase in evaporation is larger in regions with larger net radiation. This relationship holds true for $\Delta W / \Delta \mathrm{T} 2$ and $\Delta W / \Delta P$, but not as clearly as for $\Delta W / \Delta E$. This is because $2-\mathrm{m}$ temperature and precipitation are affected not only by local effects but also by largescale processes, as described in section $3 \mathrm{~d}$.

\section{d. Future work}

The simulations presented in this study contain several compromises for the sake of model simplicity. This study only considered snow-fed wetlands. However, other sources of water (e.g., rainfall or river water) should be incorporated, not only to improve the representation of wetlands at mid- and high latitudes, but also to represent the peak in wetland distribution at low latitudes (Lehner and Döll 2004). This study mainly considered two parameters: the distribution of topographic variability and the fraction of surface runoff that is temporarily stored in wetlands. However, other parameters that can affect the distribution of wetlands (e.g., soil type) should be included in future studies.

In addition, this wetland scheme does not explicitly represent water bodies. Because many wetlands are smaller than the grid scale of current climate models, a fractional wetland area is necessary to represent explicit

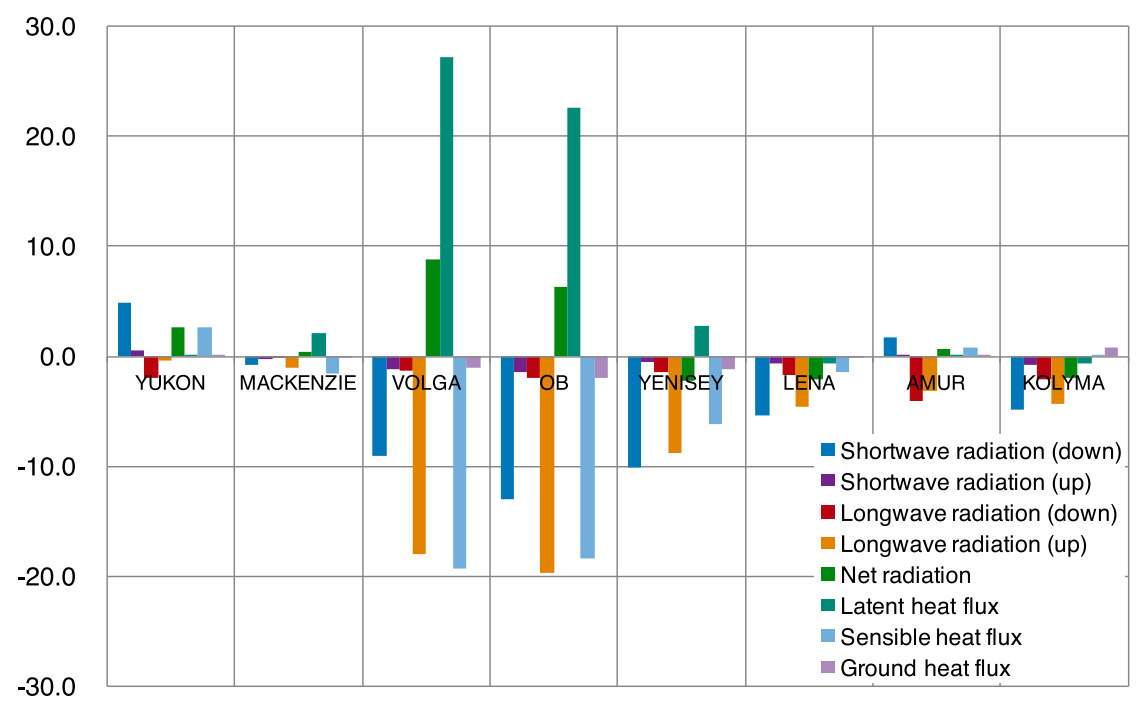

FIG. 8. Difference between the CTL and SW experiments (SW minus CTL) in each component of the surface energy budget $\left(\mathrm{W} \mathrm{m}^{-2}\right)$ averaged over eight major river basins at high latitudes in JJA. 

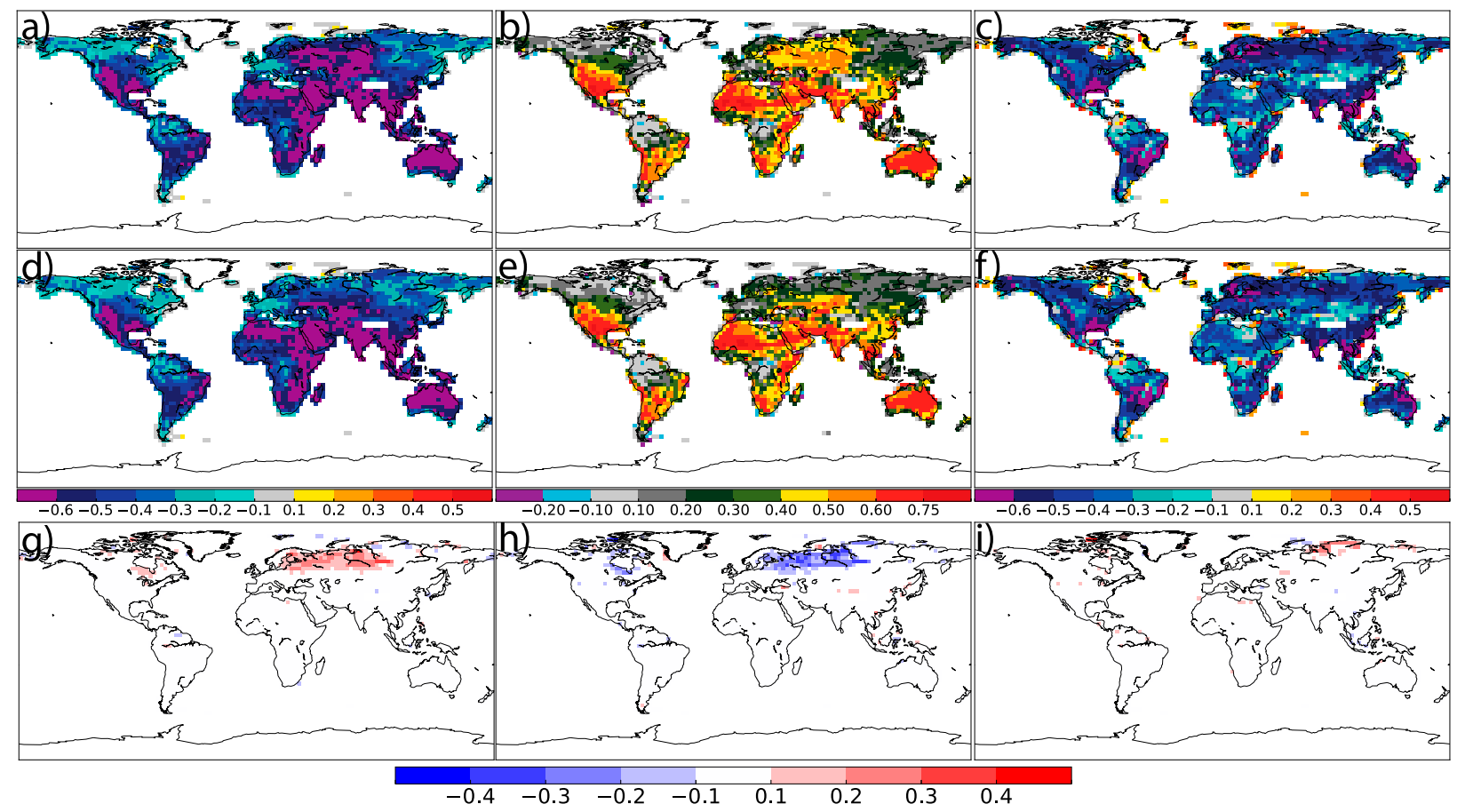

FIG. 9. Land-atmosphere coupling strength in the convective season. Correlation coefficient of (a) SM and LCL, (b) SM and EF, (c) EF and LCL in the CTL simulation, (d) SM and LCL, (e) SM and the EF, (f) EF and LCL in the SW simulation, and (g)-(i) the difference between the two simulations (SW minus CTL). To compare with Ferguson et al. (2012), the color bars are fitted.

water bodies. Therefore, the next step in the development of this model is to implement an explicit water fraction and related processes (e.g., the evaporation from the water body and change in surface albedo). Water fraction and wetland distribution datasets based on observations are available ( $\mathrm{Li}$ and Takeuchi 2016; Prigent et al. 2007; Lehner and Döll 2004; Friedl et al. 2010) and can be compared to model simulations by introducing a water fraction into the model, which will enhance reliability.

Additionally, these results may imply that the wetland parameterization likely includes hydrological dynamics in not only the wetland itself but also surface runoff process. As shown in the evaluation of river discharge, the earlier and larger peak discharge in the CTL simulation indicated that some processes that delay surface runoff were absent. In this study, we focused on wetlands; however, considering that the model structure that modulates the travel time for snowmelt to reach rivers and the method for determining parameters using offline land sensitivity experiments are based on river discharge, the results attributed to wetlands in this study might include effects of other processes that are not explicitly represented in the model. For example, the model assumes surface runoff goes to rivers instantaneously and ignores the time from the first occurrence of surface runoff until the river is reached.
Despite including the effects of wetlands, simulated peak discharge is still earlier than observations in many rivers, implying that water is routed too quickly through the catchment. Including more detailed hill slope hydrological processes might therefore be the next step. To do so, a detailed evaluation of the scheme is necessary, but this was beyond the scope of this study. Furthermore, the coupled land-atmosphere-ocean experiment using a coupled general circulation model (CGCM) with higher spatial resolution will be necessary to examine the land bias, following the precedent of Mueller and Seneviratne (2014). We expect similar

TABLE 3. Coupling strength $\tau_{\mathrm{SM}-\mathrm{LCL}}$ for eight river basins located at high latitudes. The right column shows satellite-based estimates by Ferguson et al. (2012).

\begin{tabular}{llcc}
\hline \multicolumn{1}{c}{ Basin } & CTL & SW & Ferguson et al. (2012) \\
\hline Yukon & -0.28 & -0.27 & -0.02 \\
Mackenzie & -0.23 & -0.22 & -0.03 \\
Volga & -0.62 & -0.46 & -0.11 \\
Ob & -0.61 & -0.46 & -0.17 \\
Yenisey & -0.39 & -0.32 & -0.12 \\
Lena & -0.31 & -0.31 & - \\
Amur & -0.37 & -0.36 & - \\
Kolyma & -0.3 & -0.32 & - \\
\hline
\end{tabular}




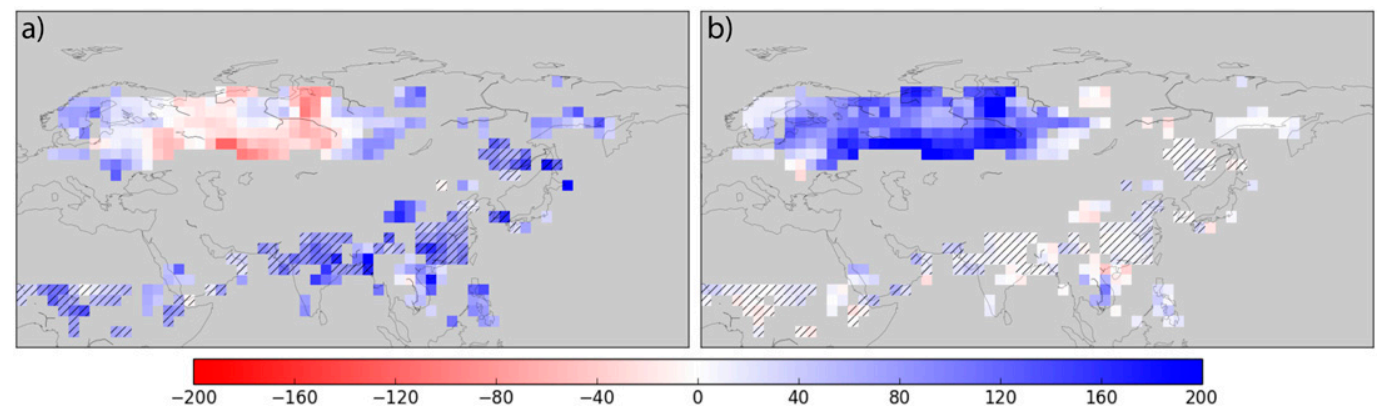

FIG. 10. Contribution of (a) the vertically integrated moisture convergence change and (b) evapotranspiration to the change in precipitation (\%) in JJA. The regions over land ice, sea, and where the absolute value of the change in precipitation was less than $0.3 \mathrm{~mm}$ are masked out (shown in gray). Hatching displays the regions where precipitation decreases.

improvement in the CGCM simulation (H. Tatebe et al. 2017, unpublished manuscript).

\section{Summary and conclusions}

This study examined the effects of snow-fed wetlands at the middle and high latitudes on surface hydrology, warm-season land-atmosphere coupling strength, and land climate. We conducted an AGCM experiment using MIROC5 with climatological monthly SST and sea ice boundary conditions, with and without a snow-fed wetland scheme. First, we compared a simulated climatology of soil moisture in JJA with satellite-based estimates. The results showed that eastern Eurasia had a wet bias and that western Eurasia and North America (except Alaska) had a dry bias. The simulated soil moisture with the
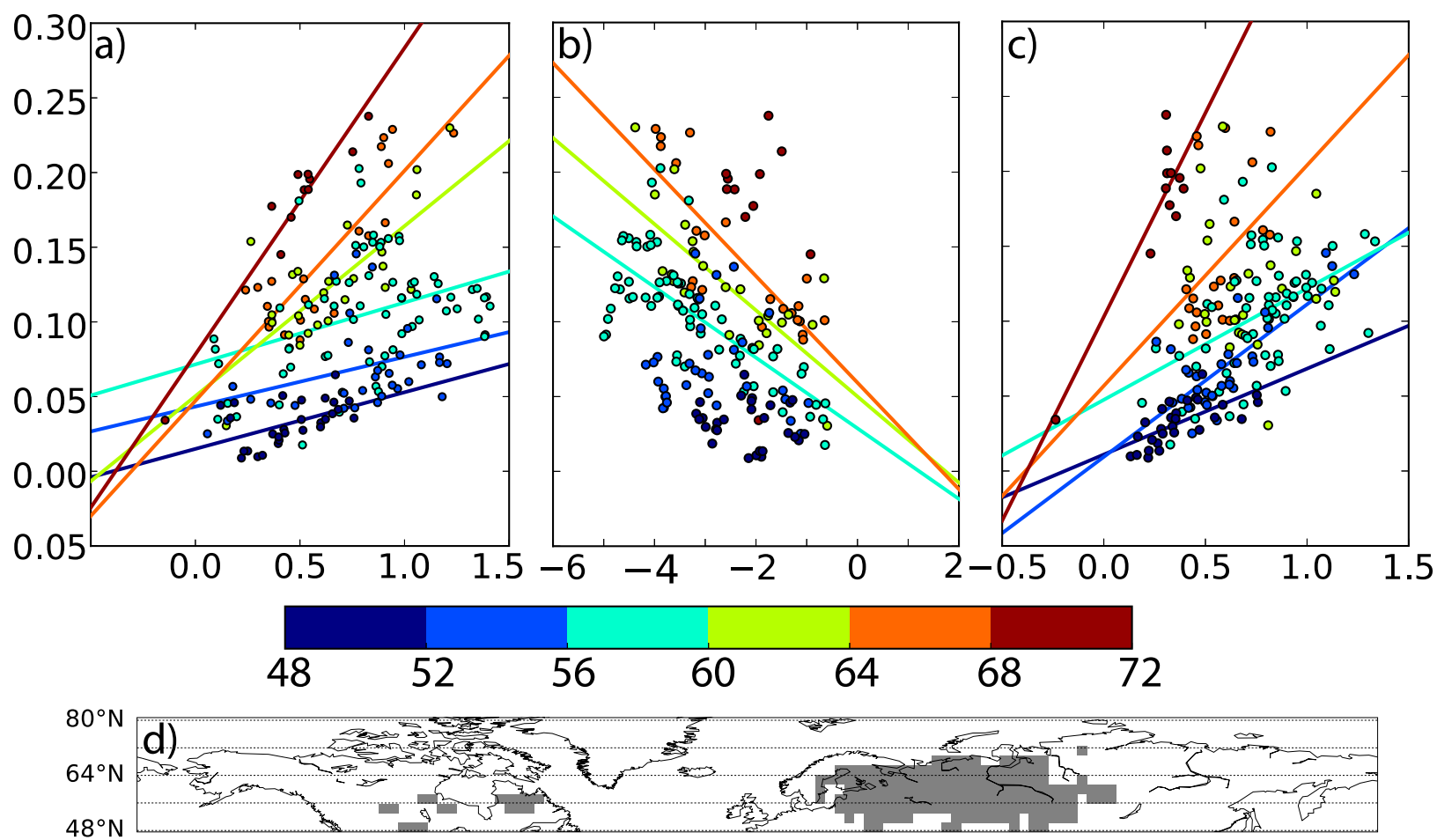

FIG. 11. (a) Scatterplot of the differences in evapotranspiration ( $x$ axis) and in soil moisture ( $y$ axis) between the two simulations in JJA. Each point represents one grid cell and its color indicates the latitude of the grid. (b),(c) As in (a), but the $x$ axis is the difference in 2-m air temperature and precipitation, respectively. For each latitude category, linear regression lines are shown if the absolute value of the correlation coefficient is greater than 0.3. (d) Gray shading indicates regions where the differences in soil moisture, evapotranspiration, 2-m air temperature, and precipitation in JJA between the CTL and SW simulations are significant at the 5\% level. 
wetland scheme increased at high latitudes. We evaluated simulated evapotranspiration and river discharge. Precipitation and surface air temperature were validated using the CRU dataset. In the experiment without the wetland scheme, a warm bias existed in most of the land area. By introducing the wetland scheme, the warm bias over mid- to high-latitude land areas decreased because the latent heat flux increased and the sensible heat flux decreased. Simulated precipitation without the wetland scheme showed a similar bias in soil moisture. It decreased in western Eurasia with the wetland scheme.

The land-atmosphere coupling strength was calculated using the rank correlation coefficient of soil moisture and the lifting condensation level. The results showed that the effects of wetlands reduce the coupling strength. The contribution of the change in local evapotranspiration was more important than in vertically integrated moisture convergence to the change in precipitation. Although the reference data we used have uncertainties, our thorough examination of the CTL experiment using multiple independent datasets showed consistent biases (results were too warm, too dry, and exhibited too strong of a land-atmosphere coupling in western Eurasia), which were improved by including the effects of wetlands.

Acknowledgments. This work was supported by the Environment Research and Technology Development Fund (S-12) of the Ministry of Environment, Japan; the Program for Risk Information on Climate Change (SOUSEI) and Integrated Research Program for Advancing Climate Models of the Ministry of Education, Culture, Sports, Science, and Technology; and the Arctic Challenge for Sustainability Project (ArCS).

\section{REFERENCES}

Balsamo, G., R. Salgado, E. Dutra, S. Boussetta, T. Stockdale, and M. Potes, 2012: On the contribution of lakes in predicting near-surface temperature in a global weather forecasting model. Tellus, 64A, 15829, doi:10.3402/tellusa.v64i0.15829.

Betts, A. K., 2004: Understanding hydrometeorology using global models. Bull. Amer. Meteor. Soc., 85, 1673-1688, doi:10.1175/ BAMS-85-11-1673.

Beven, K. J., and M. J. Kirkby, 1979: Physically based, variable contribution area model of basin hydrology. Hydrol. Sci. Bull. 24, 43-69, doi:10.1080/02626667909491834.

Bowling, L. C., and D. P. Lettenmaier, 2010: Modeling the effects of lakes and wetlands on the water balance of arctic environments. J. Hydrometeor., 11, 276-295, doi:10.1175/2009JHM1084.1.

Campoy, A., A. Ducharne, F. Cheruy, F. Hourdin, J. Polcher, and J. C. Dupont, 2013: Response of land surface fluxes and precipitation to different soil bottom hydrological conditions in a general circulation model. J. Geophys. Res. Atmos., 118, 10 725-10 739, doi:10.1002/jgrd.50627.

Cheruy, F., J. L. Dufresne, F. Hourdin, and A. Ducharne, 2014: Role of clouds and land-atmosphere coupling in midlatitude continental summer warm biases and climate change amplification in CMIP5 simulations. Geophys. Res. Lett., 41, 6493-6500, doi:10.1002/2014GL061145.

Christensen, J. H., and F. Boberg, 2012: Temperature dependent climate projection deficiencies in CMIP5 models. Geophys. Res. Lett., 39, L24705, doi:10.1029/2012GL053650.

Dirmeyer, P. A., 2011: The terrestrial segment of soil moistureclimate coupling. Geophys. Res. Lett., 38, L16702, doi:10.1029/ 2011 GL048268.

Ferguson, C. R., E. F. Wood, and R. K. Vinukollu, 2012: A global intercomparison of modeled and observed land-atmosphere coupling. J. Hydrometeor., 13, 749-784, doi:10.1175/ JHM-D-11-0119.1.

Friedl, M. A., D. Sulla-Menashe, B. Tan, A. Schneider, N. Ramankutty, A. Sibley, and X. Huang, 2010: MODIS Collection 5 global land cover: Algorithm refinements and characterization of new datasets. Remote Sens. Environ., 114, 168-182, doi:10.1016/j.rse.2009.08.016.

Harris, I., P. D. Jones, T. J. Osborn, and D. H. Lister, 2014: Updated high-resolution grids of monthly climatic observations-The CRU TS3.10 dataset. Int. J. Climatol., 34, 623-642, doi:10.1002/joc.3711.

Hirabayashi, Y., S. Kanae, S. Emori, T. Oki, and M. Kimoto, 2008: Global projections of changing risks of floods and droughts in a changing climate. Hydrol. Sci. J., 53, 754-772, doi:10.1623/ hysj.53.4.754.

IPCC, 2013: Climate Change 2013: The Physical Science Basis. Cambridge University Press, 1535 pp., doi:10.1017/ CBO9781107415324.

Kirschke, S., and Coauthors, 2013: Three decades of global methane sources and sinks. Nat. Geosci., 6, 813-823, doi:10.1038/ ngeo1955.

Kleinen, T., V. Brovkin, and R. J. Schuldt, 2012: A dynamic model of wetland extent and peat accumulation: Results for the Holocene. Biogeosciences, 9, 235-248, doi:10.5194/bg-9-235-2012.

Koster, R. D., and Coauthors, 2004: Regions of strong coupling between soil moisture and precipitation. Science, 305, 1138-1140, doi:10.1126/science.1100217.

_- and Coauthors, 2006: GLACE: The Global LandAtmosphere Coupling Experiment. Part I: Overview. J. Hydrometeor., 7, 590-610, doi:10.1175/JHM510.1.

— ization to subseasonal forecast skill: First results from a multi-model experiment. Geophys. Res. Lett., 37, L02402, doi:10.1029/2009GL041677.

Krinner, G., 2003: Impact of lakes and wetlands on boreal climate. J. Geophys. Res., 108, 4520, doi:10.1029/2002JD002597.

Lehner, B., and P. Döll, 2004: Development and validation of a global database of lakes, reservoirs and wetlands. J. Hydrol., 296, 1-22, doi:10.1016/j.jhydrol.2004.03.028.

Li, X., and W. Takeuchi, 2016: Land surface water coverage estimation with PALSAR and AMSR-E for large scale flooding detection. Terr. Atmos. Oceanic Sci., 27, 473-480, doi:10.3319/ TAO.2016.01.06.01(ISRS).

Liang, X., D. P. Lettenmaier, E. F. Wood, and S. J. Burges, 1994: A simple hydrologically based model of land surface water and energy fluxes for general circulation models. J. Geophys. Res., 99, 14 415-14 428, doi:10.1029/94JD00483.

Liu, Y. Y., W. A. Dorigo, R. M. Parinussa, R. A. M. de Jeu, W. Wagner, M. F. McCabe, J. P. Evans, and A. I. J. M. van Dijk, 2012: Trend-preserving blending of passive and active microwave soil moisture retrievals. Remote Sens. Environ., 123, 280-297, doi:10.1016/j.rse.2012.03.014. 
Melton, J. R., R. Wania, E. L. Hodson, B. Poulter, B. Ringeval, R. Spahni, T. Bohn, and C. A. Avis, 2013: Present state of global wetland extent and wetland methane modelling: conclusions from a model inter-comparison project (WETCHIMP). Biogeosciences, 10, 753-788, doi:10.5194/ bg-10-753-2013.

Mueller, B., and S. I. Seneviratne, 2014: Systematic land climate and evapotranspiration biases in CMIP5 simulations. Geophys. Res. Lett., 41, 128-134, doi:10.1002/2013GL058055.

—_, and Coauthors, 2013: Benchmark products for land evapotranspiration: LandFlux-EVAL multi-data set synthesis. Hydrol. Earth Syst. Sci., 17, 3707-3720, doi:10.5194/ hess-17-3707-2013.

Ngo-Duc, T., T. Oki, S. Kanae, and T. Ngo, 2007: A variable stream flow velocity method for global river routing model: Model description and preliminary results. Hydrol. Earth Syst. Sci., 4, 4389-4414, doi:10.5194/hessd-4-4389-2007.

Nitta, T., and Coauthors, 2014: Representing variability in subgrid snow cover and snow depth in a global land model: Offline validation. J. Climate, 27, 3318-3330, doi:10.1175/ JCLI-D-13-00310.1.

_, K. Yoshimura, and A. Abe-Ouchi, 2015: A sensitivity study of a simple wetland scheme for improvements in the representation of surface hydrology and decrease of surface air temperature bias (in Japanese). J. Japan Soc. Civ. Eng., 71, 995-960, doi:10.2208/jscejhe.71.I_955.

Oki, T., K. Musiake, H. Matsuyama, and K. Masuda, 1995: Global atmospheric water balance and runoff from large river basins. Hydrol. Processes, 9, 655-678, doi:10.1002/hyp.3360090513.

Pokhrel, Y. N., N. Hanasaki, P. J.-F. Yeh, T. J. Yamada, S. Kanae, and T. Oki, 2012: Model estimates of sea-level change due to anthropogenic impacts on terrestrial water storage. Nat. Geosci., 5, 389-392, doi:10.1038/ngeo1476.

Prigent, C., F. Papa, F. Aires, W. B. Rossow, and E. Matthews, 2007: Global inundation dynamics inferred from multiple satellite observations, 1993-2000. J. Geophys. Res., 112, D12107, doi:10.1029/2006JD007847.

Sellers, P. J., and Coauthors, 1996: A revised land surface parameterization (SiB2) for atmospheric GCMs. Part I: Model formulation. J. Climate, 9, 676-705, doi:10.1175/ 1520-0442(1996)009<0676:ARLSPF $>2.0 . C O ; 2$.

Seneviratne, S. I., T. Corti, E. L. Davin, M. Hirschi, E. B. Jaeger, I. Lehner, B. Orlowsky, and A. J. Teuling, 2010: Investigating soil moisture-climate interactions in a changing climate: A review. Earth Sci. Rev., 99, 125-161, doi:10.1016/ j.earscirev.2010.02.004.

_ , and Coauthors, 2013: Impact of soil moisture-climate feedbacks on CMIP5 projections: First results from the
GLACE-CMIP5 experiment. Geophys. Res. Lett., 40 , 5212-5217, doi:10.1002/grl.50956.

Shabanov, N. V., and Coauthors, 2005: Analysis and optimization of the MODIS leaf area index algorithm retrievals over broadleaf forests. IEEE Trans. Geosci. Remote Sens., 43, 1855-1865, doi:10.1109/TGRS.2005.852477.

Stacke, T., and S. Hagemann, 2012: Development and evaluation of a global dynamical wetlands extent scheme. Hydrol. Earth Syst. Sci., 16, 2915-2933, doi:10.5194/hess-16-2915-2012.

Takata, K., S. Emori, and T. Watanabe, 2003: Development of the minimal advanced treatments of surface interaction and runoff. Global Planet. Change, 38, 209-222, doi:10.1016/ S0921-8181(03)00030-4.

_- K. Saito, and T. Yasunari, 2009: Changes in the Asian monsoon climate during 1700-1850 induced by preindustrial cultivation. Proc. Natl. Acad. Sci. USA, 106, 9586-9589, doi:10.1073/pnas.0807346106.

Taylor, K. E., R. J. Stouffer, and G. A. Meehl, 2012: An overview of CMIP5 and the experiment design. Bull. Amer. Meteor. Soc., 93, 485-498, doi:10.1175/BAMS-D-11-00094.1.

van den Hurk, B., and Coauthors, 2016: LS3MIP (v1.0) contribution to CMIP6: The Land Surface, Snow and Soil moisture Model Intercomparison Project-Aims, setup and expected outcome. Geosci. Model Dev., 9, 2809-2832, doi:10.5194/ gmd-9-2809-2016.

Wagner, W., W. Dorigo, R. de Jeu, D. Fernandez, J. Benveniste, E. Haas, and M. Ertl, 2012: Fusion of active and passive microwave observations to create an essential climate variable data record on soil moisture. ISPRS Annals of Photogrammetry, Remote Sensing and Spatial Information Sciences, Vol. I-7, International Society for Photogrammetry and Remote Sensing, 315-321.

Watanabe, M., and Coauthors, 2010: Improved climate simulation by MIROC5: Mean states, variability, and climate sensitivity. J. Climate, 23, 6312-6335, doi:10.1175/2010JCLI3679.1.

Wik, M., R. K. Varner, K. W. Anthony, S. MacIntyre, and D. Bastviken, 2016: Climate-sensitive northern lakes and ponds are critical components of methane release. Nat. Geosci., 9, 99-106, doi:10.1038/ngeo2578.

Yamada, T. J., S. Kanae, T. Oki, and R. D. Koster, 2013: Seasonal variation of land-atmosphere coupling strength over the West African monsoon region in an atmospheric general circulation model. Hydrol. Sci. J., 58, 1276-1286, doi:10.1080/ 02626667.2013.814914.

Yoshimura, K., T. Sakimura, T. Oki, S. Kanae, and S. Seto, 2008: Toward flood risk prediction: A statistical approach using a 29-year river discharge simulation over Japan. Hydrol. Res. Lett., 2, 22-26, doi:10.3178/hrl.2.22. 